\title{
DO PROJETO POLÍTICO-PEDAGÓGICO DE ROUSSEAU: ALGUMAS CONSIDERAÇÕES
}

\author{
Wilson Alves de Paiva ${ }^{1}$
}

\begin{abstract}
RESUMO: Embora a obra de Rousseau tenha sido objeto de uma farta produção intelectual ao 11 ongo dos quase dois séculos e meio de sua existência, continuamente sofre por interpretaçóes distorcidas e leituras parciais. Com o objetivo de contribuir com essa discussão, sobretudo no que diz respeito à formação do homem, este trabalho procura discutir o processo no qual o homem natural se torna o homem civil, defendendo o ponto de vista de que se trata de um empreendimento da razão devidamente guiado pelos princípios da natureza e voltado para uma autêntica formação humana na qual o homem se realiza plenamente apenas em sua dupla condição, ou melhor, em sua condição composta de homem natural e homem civil.
\end{abstract}

Palavras-chave: Rousseau. Formação humana. Filosofia da educação.

\section{CONSIDERATIONS AROUND ROUSSEAU'S POLITICAL PEDAGOGICAL PROJECT}

ABSTRACT: Although Rousseau's work has been the subject of a rich intellectual production for almost two and a half centuries of its existence, it has continually been object of wrong interpretations and partial readings. In order to contribute to that discussion, particularly with regard to the man formation, this paper is intended to discuss the process in which the natural man becomes the civilian, defending the point of view that this is a development of reason, properly guided by the principles of nature and focused on an authentic human development, reaching the two objectives: human and political formation. That means a fully realization only in the dual role, or better, in a composed condition of natural and civilian man.

Keywords: Rousseau. Human formation. Philosophy of education.

${ }^{1}$ Pontifícia Universidade Católica de Goiás (PUC Goiás) - Goiânia (GO), Brasil. E-mail: wap@usp.br DOI: 10.1590/ES0101-73302016136649 


\title{
DU PROJET POLITIQUE-PÉDAGOGIQUE DE ROUSSEAU: QUELQUES CONSIDÉRATIONS
}

\begin{abstract}
RÉSUMÉ: Bien que l'oeuvre de Rousseau ait été l'objet d'une énorme production intellectuelle au cours de presque deux siècles et demi de son existence, elle souffre continuellement à cause d'interprétations déformées et des lectures partielles. En vue de contribuer à cette discussion, surtout en ce qui concerne la formation de l'homme, ce travail cherche à discuter le processus dans lequel l'homme naturel devient l'homme civil, en défendant l'opinion qu'il s'agit d'une entreprise de la raison légitimement guidée par les principes de la nature et dirigée vers une authentique formation humaine dans laquelle l'homme est entièrement réalisé, uniquement par sa double condition, ou plutôt dans sa condition composée d'homme naturel et d'homme civil.
\end{abstract}

Mots-clés: Rousseau. Formation humaine. Philosophie de l'éducation.

\section{Introdução}

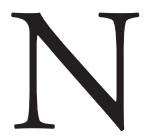

o que diz respeito à política, dois projetos são vislumbrados no pensamento do filósofo Jean-Jacques Rousseau (1712-1778): um coletivo, que numa proposta político-social defende a mudança da forma de associação mediante um contrato social; e um individual, cujo princípio é a recriação do homem natural por meio da educação, preparando-o para enfrentar a dura realidade sem, necessariamente, deixar-se corromper por ela - tal como aparece em Emílio, ou da educação (ROUSSEAU, 1973). Ambos são abstraçóes e não passam do plano normativo; servem como referencial das açóes possíveis, e não como um programa político a ser executado tal como foi escrito.

Como afirma Nascimento (1988), muitos dos revolucionários de 1889, na França, tomaram os princípios abstratos de Do contrato social (ROUSSEAU, 1999 b) como se fosse um programa político, um guia de orientação para as açôes revolucionárias. Ou seja, "tomaram o instrumento de medida e esqueceram-se do que deveriam medir. Confundiram a escala com o programa. Ou melhor, esqueceram-se dele, porque o consideraram já feito por Rousseau" (NASCIMENTO, 1988, p. 128). Dessa maneira, inauguraram uma linha de interpretação que foi amplamente difundida e aceita por diversos autores até nossos dias: buscar soluçóes fáceis e aplicaçóes práticas das reflexóes empreendidas por Rousseau, gerando até mesmo algumas interpretaçóes equivocadas - como, por exemplo, comparar Rousseau a Marx na perspectiva da igualdade igualitária socialista (DELLA VOLPE, 1982). 
Uma leitura superficial das obras do referido filósofo leva, geralmente, a muitos equívocos. É necessário um estudo mais aprofundado para captar as nuanças que existem no conjunto de seus escritos e, portanto, poder compreender a unidade que lhe dá sentido. Outra interpretação errônea é pensar que não há formação política no seu projeto pedagógico, tampouco a defesa de uma educação pública, uma vez que em Emílio ou da educação (ROUSSEAU, 1973) se vislumbra a formação do homem, e não a do cidadáo. Embora não pareça, Rousseau persegue os dois objetivos, mas, se não expóe em Emílio ou da educação uma educação pública à moda de Platão - na república, ou tal como defende em Consideraçôes sobre o governo da Polônia e sua reforma projetada (ROUSSEAU, 1982) —, é porque o autor não se propóe a tratar de aplicaçôes particulares, de formas específicas de educação, porém reflete sobre uma arte esquecida em seu tempo: a arte de formar os homens, por uma abordagem generalista pela qual se almeja a formaçáo de um homem natural que vai, entretanto, viver no meio social.

Assim, tomando a sociedade e o homem como devem ser, Rousseau contribui com a discussão analisando, sobretudo em Emílio ou da educação (ROUSSEAU, 1973), a possibilidade de reconciliação entre natureza e cultura, propondo uma formação que englobe os dois ideais e consiga superar os conflitos gerados pela sociedade. $\mathrm{O}$ eu não deixa de ter dimensão política, a qual se pode chamar de verdadeira arte de reconfiguração do homem (PAIVA, 2010), e de reencontrar a natureza pela arte: "Reencontramos a natureza no momento em que a arte e a cultura atingem seu mais alto grau de perfeição: 'A arte consumada torna-se novamente natureza"” (STAROBINSKI, 1991, p. 43), pois a boa condução do homem em sua trajetória social deve valer-se dos pressupostos naturais e intrínsecos, transformando as estruturas da vida em sociedade.

\section{A escala bem aplicada}

Nesse ponto se faz necessário aplicar a ideia de escala, citada anteriormente, que Rousseau explicita no livro quinto de seu Emílio ou da educaçáo (ROUSSEAU, 1973), logo antes de apresentar ao discípulo o resumo de Do contrato social: "Antes de observar é preciso criar regras para as observaçóes; é preciso uma escala para as medidas que tomamos. Nossos princípios de direito político são essa escala. Nossas medidas são as leis políticas de cada país" (ROUSSEAU, 1973 , p. 542). Da mesma forma que o filósofo não tem em mente a aplicação prática de Do contrato social (ROUSSEAU, 1999b), não tem em mente a realização da proposta pedagógica de Emílio ou da educação (ROUSSEAU, 1973). Emílio pode ser entendido como uma escala em termos formativos entre a menor e a maior aproximaçấo do núcleo social, do mundo da cultura e da representaçáo. Como afirma Boto (2002, p. 370), "o Emílio é antes, um relato, uma metáfora, uma suposição ou categoria operatória, que, enquanto tal, remeteria às essências. 
Sendo assim, não teria jamais a pretensão de ser aplicado como método educativo de crianças reais", isto é, uma escala.

Bem demonstrado por Salinas Fortes (1985), Rousseau desenvolveu a ideia de escala na vida política. Como um termômetro, a escala serve para medir a variação "entre o grau mínimo de fusão e coesão e um grau máximo de separação e divisão" (SALINAS FORTES, 1985, p. 90). A variação depende das condiçôes concretas de cada realidade sobre a qual serão aplicadas suas ideias. De um mínimo a um máximo de representação, é assim que evolui também aqui a escala, o instrumento de medida. Alguma representação é inevitável, já que o corpo coletivo constitui uma abstração que necessita do seu outro, do indivíduo, para encarnar. $\mathrm{O}$ caráter náo natural ou artificial dessa realidade nova, que é o corpo político, implica necessariamente a mediação por intermédio do indivíduo natural, suporte e base real sobre a qual se sustenta a coletividade. $\mathrm{O}$ cidadão não suprime efetivamente o homem, o indivíduo natural. A dimensão pública deve predominar na república e, nesse caso, a solução da antinomia entre o ser e o parecer não se dá pela restauração do ser, tornada impossível, mas pela realização, na medida do possível, do cidadão, ou seja, do indivíduo que tem existência na cidade (SALINAS FORTES, 1997).

Por um lado, há o esforço do preceptor em levar Emílio a contemplar a vida simples do homem do campo, suas festas e toda sua maneira de ser e agir. Por outro, o discípulo precisa fazer uma leitura política da vida social, procurando entender como ela se organiza, como os homens agem, como se apresentam diante dos outros e como se mascaram. Só assim será capaz de medir a realidade, posicionar-se nessa escala, de modo a evitar os efeitos depreciadores do disfarce e viver o mundo da representação de forma a tirar-lhe proveito para si e para os outros. Logo, entre o imperativo de evitar as máscaras e a inexorabilidade de usá-las, o homem social pode representar um papel cívico, isto é, agir menos em proveito próprio e, sim, com vistas ao bem comum.

Se tal realização for possível, teremos aí a conjugação dos dois ideais que interligam a obra de Rousseau e despontam como referenciais máximos de seu pensamento, os quais abraça por toda a vida: a natureza e a sociedade. Presentes em sua concepção de homem, tais ideais se transformam em elementos constitutivos de um ser que sai do estado de natureza mediante o aperfeiçoamento e adentra no estado de sociedade, mantendo, contudo, sua natureza. Essa duplicidade encontra na obra de Jimack (1960, p. 96) uma interpretação mais ampla: "Ele não é duplo, é composto", até mesmo reafirmando a disposição de Rousseau na primeira versão de Emílio ou da educação (manuscrit favre): "Nós não somos precisamente duplos mas compostos" (ROUSSEAU, 1964, p. 57). Composto porque um complementa o outro em suas imperfeiçóes.

O modo como o homem supera o conflito e se integra a um plano de conjugação dos dois ideais é uma questão inteiramente pedagógica, uma tarefa moral 
que pode ser executada pelas instituiçóes políticas e educacionais que atuam sistematicamente na formação do homem e do cidadão, buscando sempre uma síntese entre os dois. Estamos diante de uma tarefa cujo processo faz lembrar o ideal da paideia, embedido da essência estoica e iluminado pelas reflexóes transcendentes de Pascal. O resultado de tudo isso é o belo projeto de formação humana expresso ao longo do texto Emílio ou da educação (ROUSSEAU, 1973), no qual a ação formativa tem por princípio a valorização incondicional da natureza e, como não poderia deixar de ser, é a melhor maneira de desnaturar o homem de forma que ele possa bem viver entre os seus. Como diz Vargas (1995) em sua Introduction à l'"Emile" de Rousseau, uma verdadeira ideia de política natural que se realiza pela via da educação.

Mesmo tendo sido contrário às diversas formas de representação, Rousseau sabia que vivemos um mundo simbólico, representativo e cuja relação com o outro é imperiosa. Nessa relação, cabe à ação educativa "exercitar o educando contra os sortilégios do jogo deformante da representação" (SALINAS FORTES, 1997, p. 29), ressaltando que as faculdades representativas podem ser utilizadas para a promoção de uma vida virtuosa e compatível com as necessidades cívicas. Ou seja, em vez de criar uma representação defeituosa, a educação possibilita as condiçóes propícias para o pleno desenvolvimento das faculdades humanas e seu emprego contra a transgressão do coração humano. Considerando que os vícios e a transgressão são alimentados pelas paixões, é preciso então controlar e dominar essas paixóes. Estas não são fenômenos da natureza, mas da natureza humana, e, semelhantemente às forças fenomênicas do passado, as atuais podem também entrar em erupção e dominar a mentalidade humana a ponto de fazer o homem se esquecer de sua bondade original, de sua virtuosidade adquirida e dos princípios da consciência implantados pelo Criador.

Como atesta Derathé (1949), bondade e virtude são diferentes. Enquanto a primeira é um dom da natureza, a outra deve ser uma conquista do próprio homem no âmbito de bem conduzir sua vontade e sua razão. "O que é então um homem virtuoso?”, pergunta Rousseau (1973, p. 525). E responde: "É aquele que sabe dominar suas afeiçóes, pois então segue sua razão, sua consciência, faz seu dever, mantém-se dentro da ordem e nada o pode afastar dela" (ROUSSEAU, 1973, p. 525). Nisso concordamos com Vargas (1995), pois o processo pedagógico de Emílio faz com que as disposiçóes naturais sejam preservadas e aproveitadas, embora com outras características, no mais aproximado sentido.

Afinal de contas, o que é a virtude a não ser a representação social da bondade natural? Se, depois de obter conhecimento e desenvolver sua razão, o homem consegue seguir a voz de sua consciência, faz o que deve ser feito e não segue o que as paixóes inflamadas lhe insinuam, ele terá o mérito de ter sido bom para si mesmo e para os seus semelhantes. Emílio é o protótipo desse homem virtuoso, porque conserva a bondade e os traços gerais do homem natural vivendo em sociedade, cumprindo seu papel. 
A boa socialização é aquela que consegue, portanto, superar a contradição criada pela ordem social e proporcionar uma realidade nova. A boa educação é aquela capaz de melhor preparar o homem para enfrentar essa realidade, robustecendo-o contra o império da opinião e contra o jogo deformante da representação. Ou seja, o processo de civilização deve contar com um trabalho político e pedagógico que amplie as possibilidades de convivência com o outro sem o fermento do amor-próprio, da alienação e das situaçóes que degradam a condiçâo humana. Isto é, deve-se arrancar o homem de si mesmo e fazer dele uma persona.

\section{Emílio e seu papel}

Tomando a frase de Rousseau (1973, p. 15) — "na ordem social, em que todos os lugares estáo marcados, cada um deve ser educado para o seu" —, passamos a questionar: que papel social teria um homem que desde a infância foi isolado da sociedade? Por isso Emílio é tão somente isolado, em princípio, da agitação do núcleo urbano-social e dos efeitos que ela causa. Afastado da urbanidade, tem sua atenção desviada para a vida campestre, que, por sinal, pode ser tomada como um exemplo de maior proximidade das condiçôes naturais. No mundo rural, embora ainda parte da sociedade, há menos representação e as famílias camponesas vivem de forma simples, sem luxo e sem o jugo do petulante amor-próprio. Lembrando que o amor-próprio nasce, segundo Rousseau (1999a), das relaçóes sociais quando um sente o desejo de ser melhor que o outro. Como consequência disso, tais relaçóes se desfiguram pelo prazer da superioridade, do prestígio e da dominação que acarretam. O fogo das vaidades alimenta o amor-próprio de tal forma que a sociedade fica inviável, a não ser quando o amor-próprio é devidamente educado e utilizado como fonte de estima (NEUHOUSER, 1993), pois, diferentemente do que Bloom sugere em sua introdução à versão inglesa de Emílio ou da educação, que o homem seria bom apenas em condiçóes nas quais o amor-próprio não se manifesta, Rousseau sinaliza uma válvula de escape, isto é, a possibilidade de uma educação virtuosa como antídoto à variante negativa do amor-próprio (DALBOSCO, 2014).

Esse é, portanto, o cenário propício para iniciar a educação de alguém que aos poucos vai sendo reintroduzido na urbanidade e projetado para viver plenamente sua condição civil. Como diz Rousseau (1973, p. 379):

Emílio não é feito para permanecer sempre solitário; membro da sociedade, deve cumprir seus deveres. Feito para viver com os homens, deve conhecê-los. Conhece o homem em geral, resta-lhe conhecer os indivíduos. Sabe o que se faz no mundo: resta-lhe saber como nele se vive. É tempo de mostrar-lhe o exterior desse grande palco cujos jogos interiores já conhece. 
Por esse motivo, as viagens empreendidas pelo preceptor e por seu discípulo acontecem na idade adulta, quando o jovem está prestes a contrair matrimônio e assumir seu papel de homem em toda sua plenitude: marido, pai, preceptor, trabalhador e indivíduo guardador dos preceitos civis e útil à coletividade: "Deves viver no meio deles, ou ao menos em lugar onde possas ser-lhes útil na medida de tuas forças, e onde saibam ir buscar-te se precisarem de ti" (ROUSSEAU, 1973, p. 561). O trecho "na medida de tuas forças" revela um cidadão condicionado às próprias capacidades pessoais, diferente de um cidadão espartano, como Placedemônio Pedarete, que se apresenta para ingressar no conselho dos 300 e, diante da recusa, fica satisfeito por existir 300 concidadãos mais dignos que ele para a tarefa. Mas o trecho "onde saibam ir buscar-te se precisarem de ti” (ROUSSEAU, 1973, p. 13, grifo meu) aproxima Emílio do cidadão Pedarete, que, tendo sido recusado, voltou à faina cotidiana na expectativa de um dia ser útil no conselho ou em qualquer outra atividade cívica. Até mesmo os filhos da mulher espartana que morreram na guerra talvez estivessem vivos e cuidando de seus afazeres se não tivesse ocorrido a guerra. O sentimento que a mãe demonstrou pela vitória bélica é um sacrifício diante de uma grande necessidade civil. Se Emílio será capaz de um sacrifício como esse, só a premência da necessidade poderá dizer. Terá ele forças para enfrentar tal disposição? Será essa sua vocação? A resposta parece estar na frase que Rousseau coloca logo em seguida e que pode ser considerada como chave para entender todo o pensamento do filósofo quanto à formação humana:

Que se destine meu aluno à carreira militar, à eclesiástica ou à advocacia pouco me importa. Antes da vocação dos pais, a natureza chama-o para a vida humana. Viver é o ofício que lhe quero ensinar. Saindo de minhas mãos, ele não será, concordo, nem magistrado, nem soldado, nem padre; será primeiramente um homem. Tudo o que um homem deve ser, ele o saberá, se necessário, táo bem quanto quem quer que seja; e por mais que o destino o faça mudar de situação, ele estará sempre em seu lugar (ROUSSEAU, 1973, p. 15).

Trata-se, como podemos ver, de uma formação geral, de uma educação de princípios e da preparação do homem para as decisões que forem necessárias em sua vida. Independentemente da escolha que vier a tomar, os princípios da natureza estão implantados no coração para guiá-lo em suas açóes, contudo a educação de Emílio não deixa de lado os detalhes práticos nem o refinamento. Até porque o que aparece na obra é uma educação refinada que tende a desenvolver em Emílio um conjunto de percepçóes práticas, uma sensibilidade estética e uma compreensão cultural que não podem ser encontradas facilmente. A música, as viagens, os exercícios físicos, as relaçôes morais e a sensibilidade estética estão presentes em seu currículo por mais informais que sejam. Até mesmo sua profissão não é qualquer tipo de formação, pois o ofício de marceneiro requer inteligência 
e criatividade na produçáo dos artefatos que agregam o refinamento estético e a utilidade. Náo podemos esquecer também que a educação musical de Emílio foi bem mais intensa do que Rousseau descreve no livro III: além de conhecer a produção musical, afinava o cravo de Sofia, aperfeiçoava seu canto e era capaz de fabricar alguns instrumentos. Porém, "em lugar de ser artificioso para agradar, bastará ser bom; ao invés de ser falso para lisonjear as fraquezas de outrem, bastará ser indulgente" (MARQUES, 2002, p. 393).

A ação formativa rousseauniana é propedêutica e visa à vida social. Mas, antes da plenitude de uma vida civil e cidadã que ela possa propiciar, é preciso ensinar os valores universais e desenvolver no educando sua humanidade. Ele será primeiramente um homem e, mesmo depois de seguir alguma carreira que permita desempenhar seu papel civil, não esquecerá a dimensão humana nem sua própria natureza, uma vez que estará sempre em seu lugar. Não podemos esquecer que o primeiramente ali posto permite entender que pode haver dois níveis nessa formação: o de homem e depois o de cidadão. O prodígio da arte e a obra-prima da educação acontecem se os dois objetivos forem alcançados. Resulta, nos termos que empregamos, no homem reconfigurado, isto é, portador de uma figura nova, um papel novo que o capacita viver para si mesmo e, por extensão, para os outros: "Estou à espera de que me mostrem esse prodígio, a fim de saber se é homem ou cidadáo, ou como se arranja para ser a um tempo um e outro" (ROUSSEAU, 1973, p. 13-14).

Quando Rousseau afirma que desses dois objetivos decorrem duas formas de instituições contrárias, isto é, uma familiar e doméstica e outra pública e comum, circunscreve a oposição entre eles tendo em consideração a realidade dada. O principal alvo de sua crítica é a educação de sua época, bem como a ordem social e política estabelecida. Tanto que o autor afirma logo em seguida a inexistência da instituição pública, da pátria, do cidadão e até mesmo da escola pública: "Não encaro como uma instituição pública esses estabelecimentos ridículos a que chamam de colégios" (ROUSSEAU, 1973, p. 14). Podemos ver que o indignado filósofo está se referindo aos colégios de sua época, que não formavam nem para um nem para o outro propósito, no entanto, titubeando entre um e outro, acabavam formando o que Rousseau chamou de "homem de duas caras" (ROUSSEAU, 1973, p. 14). Ora, diante de uma realidade como essa, isto é, uma vida social depravada e cheia de instituiçóes corruptas, como acreditar nelas e entregar-lhes os filhos para que sejam educados?

Por conseguinte, "resta enfim a educaçáo doméstica ou da natureza" (ROUSSEAU, 1973, p. 15). Resta a verdadeira ação educativa por excelência, ou seja, aquela que tem seu início no nascimento, prossegue por toda a vida num movimento contínuo de desenvolvimento dos princípios que resumem o chamado da natureza no coração do homem e prepara para viver qualquer situação, até mesmo a de representar um papel determinado no jogo das representaçóes sociais - po- 
dendo ser um simples coadjuvante, ou o ator principal no teatro da vida pública. Não parece ser outro o papel de Emílio.

\section{Homem e cidadão}

"Faremos de Emílio um cavaleiro andante, um paladino?", questiona Rousseau (1973, p. 280) diante dos dois ideais de formaçáo. Ou seja, Emílio será como o nobre cavaleiro de $L a M a n c h a^{1}$, que se lança à tarefa de salvar o mundo com sua heroica bravura, ou será como o solitário Robinson Crusoé, que, após ter saído de sua ilha deserta e viajado todo o mundo, ouve de um príncipe russo que a verdadeira grandeza neste mundo é ser dono de si mesmo?² Emílio tentará salvar o mundo ou salvará a si mesmo? Resumindo, será um homem ou um cidadão? Vale repetir que, em resposta ao seu próprio questionamento a respeito da formação de Emílio para que seja um paladino, Rousseau (1973, p. 280, grifo meu) afirma que nada tem a declarar e que o "primeiro dever" de Emílio é para consigo mesmo.

Novamente, o termo primeiro abre uma possibilidade de interpretação na qual Emílio terá diversos deveres, tanto individuais como coletivos, mas primeiramente deve cuidar de si mesmo, dedicando-se ao exercício socrático do autoconhecimento, dominando seus sentimentos e controlando suas paixóes. Como Rousseau (1973) afiança que se trata de um "primeiro dever", podemos presumir a existência de outros deveres. Se não fosse assim, por que diversas liçóes morais e resumo de Do contrato social estariam entre as liçóes de Emílio? Nesse sentido, o filósofo comenta:

Aquele que, na ordem civil, deseja conservar a primazia da natureza, não sabe o que quer. Sempre em contradição consigo mesmo, hesitando entre suas inclinaçóes e seus deveres, nunca será nem homem nem cidadáo; não será bom nem para si nem para outrem. Será um dos homens de nossos dias, um francês, um inglês, um burguês; não será nada (ROUSSEAU, 1973, p. 13, grifo meu).

Perante essa aparente contradição de propósitos, qual medida seria a correta para delinearmos a formação e definirmos os traços reconstituintes da figura humana? Formar o homem ou o cidadáo? Em nossa opinião, o paradoxo é proposital, pois tem a intenção de fazer o leitor sentir o drama do antagonismo existencial que o homem sofre no convívio interno das duas figuras: homem e cidadão. Como diz Francisco (2008, p. 55-56): "Considerando que estamos diante de um autor que domina como poucos a arte da escrita, é improvável que a contradição do trecho lhe passasse desapercebida ou fosse involuntária”. Ou seja, provocar uma reflexão em torno da divisão interna do agente moral, seus conflitos e a urgência de se superar tal condição, principalmente se atingir um ponto de 
acordo, de harmonia e convivência entre as duas disposiçóes, sem a "primazia" de nenhuma. Atingir, portanto, o "duplo objetivo" seria a superação dos conflitos e a eliminação das contradições tão necessárias à felicidade do homem. Como vivemos na ordem civil, não podemos propor a primazia, isto é, a prioridade ou a supervalorização da dimensáo natural. O que deve haver é uma conjugaçáo de ambas tanto na organização geral da sociedade quanto na formação específica do homem. São duas dimensões presentes em todo o ato formativo que acontece desde o nascimento da criança (plano individual) até sua plena constituição como cidadão (plano coletivo).

Basta lembrar que, antes de empreender as viagens com o discípulo, o preceptor comenta: "Tornando-vos chefe de família, ides tornar-vos membro do Estado" (ROUSSEAU, 1973, p. 529). E prossegue perguntando:

E que é ser membro do Estado? Sabei-o? Estudastes vossos deveres de homem, mas os do cidadão conhecei-os? Sabeis o que sejam governo, leis, pátria? Sabeis a que preço vos é permitido viver e por quem deveis morrer? Acreditais ter tudo aprendido e nada sabeis ainda. Antes de terdes um lugar na ordem civil, aprendei a conhecer e a saber qual vos cabe (ROUSSEAU, 1973, p. 529).

Ora, uma educação puramente doméstica que objetiva formar táo somente o indivíduo não parece ser o plano formativo que consta em Emílio ou da educação (ROUSSEAU, 1973), tampouco o desejo de Rousseau. Importa repetir o questionamento que o autor coloca no início da obra: "Mas o que será para os outros um homem unicamente educado para si mesmo?" (ROUSSEAU, 1973, p. 15). O que nos leva a concordar com Francisco (1998) que não se deve levar muito a sério a afirmação de Rousseau, sobre sua pretensão de formar exclusivamente o homem e não o cidadão, ou pelo menos fazer uma interpretação literal dela. Afinal, se o filósofo garante não ser possível formar o homem e o cidadão "ao mesmo tempo" (ROUSSEAU, 1973, p. 12), também assegura, como já vimos, que, "se o duplo objetivo que se propõe pudesse porventura reunir-se num só, eliminando as contradiçóes do homem, eliminar-se-ia um grande obstáculo à sua felicidade" (ROUSSEAU, 1973, p. 15). Expressão do desejo, a frase não foi inseri$\mathrm{da}$ aleatoriamente, mas reflete o próprio objetivo da obra: superar o antagonismo e a oposição entre os dois objetivos. Como diz Francisco (1998, p. 61):

Essas palavras, talvez as mais importantes de toda a parte inicial do Emílio acerca dos princípios que governam a educação humana, expóem claramente o propósito maior do autor na obra: trata-se não de formar apenas o homem natural, o indivíduo, o ser da casa e da pequena sociedade da família, mas de buscar, na mesma medida, formar o cidadão, o homem social, o ser da sociedade stricto sensu. É evidente, portanto, que o 
Emílio não pode ser simplesmente lido como uma obra de educação doméstica, de formação do homem natural. Há aí, sem dúvida alguma, a intenção de formá-lo. Mas, há, igualmente, por outro lado, a intenção de encontrar as vias para se chegar ao cidadão.

Apesar de desejável, a tarefa não é fácil. Demanda, como se figura nos demais livros de Emílio ou da educação, muito tempo: "Não desanimei nem me apressei: a instrução das crianças é uma profissão em que é preciso saber perder tempo para ganhá-lo" (ROUSSEAU, 1973, p. 142), assim como uma laboriosa dedicação ao desenvolvimento paulatino da sensibilidade ativa, ou seja, o desenvolvimento dos princípios da moral, dos bons costumes e das obrigaçóes cívicas. Uma arte voltada para a eliminação completa da contradição entre a natureza e a cultura.

Não é uma arte qualquer, daquelas que servem apenas para envaidecer o ego de cada um, aumentar o luxo e prover as camadas mais esclarecidas de artefatos fetichizados pela cultura aristocrática e burguesa que, restabelecida juntamente com as ciências, ajudou a corromper as almas. $\mathrm{O}$ sentido de arte aqui empregado é o formulado por Starobinski (1987, p. 12, tradução livre): "Arte é qualquer método que tende a promover e aperfeiçoar um fenômeno natural, ordená-lo e fazê-lo agradável e útil”. Ou seja, trata-se de uma ação ponderada e minuciosa cujo esmero está na junção da ars e da techné num plano de ação humana que substitua a ordem dos valores naturais por uma ordem artificial que consiga resgatar a dignidade humana, a fim de que seja útil à sociedade como um todo. Eis aqui um verdadeiro axioma da educação moral que sustenta a construção ontológica rousseauniana nas bases da expansão antropológica que os três mestres propiciam.

Nesse aspecto, podemos dizer, então, que Emílio é um exemplo de obra de arte na qual o homem aparece como fenômeno natural e é desnaturado gradativamente até atingir o nível do homem social, membro de uma comunidade e zeloso de seus deveres. Emílio é o prospecto do homem natural que vai viver na ordem civil entre seus semelhantes, amando-os, respeitando-os e ajudando-os em todas as suas necessidades. Possui uma ampla formação política que envolve, até mesmo, um senso de cosmopolitismo burguês. Por isso, toda a obra é rica em sugestões morais e preceitos inteiramente políticos.

Destarte, ele representa a formação do homem moderno do modo como Rousseau o concebe, isto é, um homem livre cujo desenvolvimento integral depende da exigência pela liberdade, mas zeloso de seus deveres para com sua espécie. Em sua universalidade, lança mão do cosmopolitismo para poder analisar todas as formas de governo, a maneira como se organizam os estados e se dar ao luxo de escolher um entre estes para viver. Melhor do que isso, o homem moderno é capaz de recriar essas formas e dar um novo modelo à sociedade, seguindo o 
contrato social ou a voz da própria consciência. Emílio é, portanto, quem melhor se aproxima do ideal, numa escala de valores e diante da realidade que Rousseau tinha à frente.

No fim de sua formação, após ter retornado de uma jornada pelos países europeus, já adulto e preparado para o matrimônio, o jovem ouve a seguinte fala de seu mestre, que o faz entender melhor a questão da liberdade e os objetivos de sua formação:

Se te falasse dos deveres do cidadáo, tu me perguntarias onde está a pátria e pensarias ter-me confundido. Tu te enganarias entretanto, caro Emílio; pois quem não tem uma pátria tem ao menos um país. Há sempre um governo e simulacros de leis sob os quais viveu tranquilo. Que importa se o contrato social não foi observado, desde que o interesse particular tenha sido protegido como o fizera a vontade geral, desde que a violência pública o tenha garantido contra as violências particulares, desde que o mal que viu fazerem o tenha levado a amar o que era bem, desde que nossas próprias instituiçóes o tenham feito conhecer e odiar suas próprias iniquidades? Ó Emílio, onde está o homem de bem que nada deva a seu país? Quem quer que seja, ele lhe deve o que há de mais precioso para o homem, a moralidade de suas açôes e o amor à virtude. Nascido no fundo de um bosque, teria vivido mais feliz e mais livre; mas nada tendo a combater para seguir suas inclinaçóes, teria sido bom sem mérito, não teria sido virtuoso, e agora ele o sabe ser apesar de suas paixóes (ROUSSEAU, 1973, p. 560).

Embora encontremos em Emílio ou da educação (ROUSSEAU, 1973) referências às duas dimensôes, isso não significa sistemas ${ }^{3}$ no sentido que Rang (1964) advoga. Para ele, há um sistema no plano da educação doméstica voltado para a formação do indivíduo, como exposto em Emílio ou da educação (ROUSSEAU, 1973); e outro no plano de educação pública, a qual deve ser empreendida pelo Estado e cujo fim é a preparação do cidadão, como discutido em Consideraçóes sobre o governo da Polônia e sua reforma projetada (ROUSSEAU, 1982). Em nossa opinião, suas reflexóes não criam sistemas, mas buscam discutir a educabilidade do homem, a qual pode acontecer em duas dimensóes distintas, ou fundamentada por dois objetivos até mesmo contrários, porém esforçando-se para a superação dos conflitos e paradoxos gerados na tentativa de conjugar dois objetivos.

O plano da superação tem em vista englobar a dimensão individual e a dimensão pública num só projeto, num só esforço educativo, que começa com os pais (corresponsáveis pelo processo educador da sociedade) e pode ser auxiliado por parentes, vizinhos e demais conhecidos, por preceptores e até mesmo pelas instituiçóes políticas, podendo ter seu apogeu no Estado. Se isso náo 
ocorre em Emílio ou da educação (ROUSSEAU, 1973), não quer dizer que náo esteja no plano de formação humana que Rousseau desenvolve. Quando analisamos o conjunto de sua obra, podemos afirmar que na reforma da sociedade as instituiçóes desnaturadoras poderão tomar o exemplo de educação exposto em Emilio ou da educação (ROUSSEAU, 1973) para inspirar a ação educativa pelas vias que vêm expostas em Consideraçóes sobre o governo da Polônia e sua reforma projetada (ROUSSEAU, 1982) e em Do contrato social (ROUSSEAU, 1999b). Da mesma forma, o processo pode ter seu início no campo, isto é, na ruralidade, contudo terminar na urbanidade, no movimento político da cidade e na plena convivência com seus semelhantes. Se houvesse uma sistemática separação entre educação pública e educação privada, sendo esta última negativa e a primeira positiva, Rousseau (1982) não teria dito em Consideraçóes sobre o governo da Polônia e sua reforma projetada (ROUSSEAU, 1982), comentando sobre os exercícios públicos, o seguinte:

Os pais que preferirão a educação doméstica e farão educar seus filhos debaixo de seus olhos, devem, náo obstante, enviá-los a esses exercícios. Sua instrução pode ser doméstica e particular, mas seus jogos devem sempre ser públicos e comuns a todos; pois não se trata aqui apenas de ocupá-los, de formar para eles uma constituição robusta, de torná-los ágeis e atléticos, mas de acostumá-los desde cedo à regra, à igualdade, à fraternidade, às competiçôes, a viver sob os olhos de seus concidadãos e a desejar a aprovação pública (ROUSSEAU, 1982, p. 38).

Mais uma vez afirmamos que há, em vez de dois sistemas, duas fases, ou dimensōes de um processo formador, as quais lembram as fases pelas quais o homem deve passar em seu desenvolvimento cognitivo, ou seja, a fase da infância, com toda sua idiossincrasia, e a fase de homem. Na primeira é a natureza que manifesta sua latência, seu imperativo e plasma na alma — os elementos ontológicos primordiais que sustentam o conceito de humanidade. Na segunda fase, depois de bem estruturado pela natureza, o homem adentra no mundo das representaçôes e das inter-relações necessárias à realidade social e à construção do político. Dois planos que se entrelaçam e se realizam sem primazia de um ou de outro.

Para melhor compreendermos o projeto pedagógico de Rousseau, é preciso entendê-lo como um projeto socioeducacional, um empreendimento cuja arte está na reconfiguração da imagem deteriorada do humano na perspectiva do social. A obra-prima está no resgate da natureza humana nessa nova figura sem, contudo, ferir os princípios da coletividade. No entanto a autenticidade e, para os termos que utilizamos neste trabalho, a arte estão na capacidade de fazer possível esse tipo de homem sem, todavia, matar nele sua individualidade. Por isso, faz-se importante concordar com Cobban (1964, p. 164, tradução livre): 
Ele está pronto a rejeitar qualquer teoria que afunda por completo o individual na massa coletiva de forma a roubar-lhe sua capacidade de liberdade moral. Mesmo quando exalta a comunidade e parece exigir o sacrifício do indivíduo, é porque torna-se necessária uma identificação voluntária do indivíduo para com a comunidade, da qual é membro, a fim de atingir seu bem-estar moral.

Discordamos, entretanto, de Cotta (1965, p. 172), que defende a supremacia total do social sobre o individual, até porque, como afiança o próprio autor (COTTA, 1965, p. 165), "o objeto de sua filosofia política é o de efetivar a reconciliação entre o indivíduo e o estado”. Portanto, não há supremacia de nenhum dos dois, mas a reconciliação e a possível realização dos dois objetivos.

\section{Considerações finais}

Nessa perspectiva, Emílio representa o ser universal, o sujeito ético, o sábio cidadão do mundo que pode escolher qualquer lugar para viver, uma vez que foi educado segundo a lógica da natureza, adequando-se a qualquer realidade sem deixar-se corromper. Mais do que isso, educado para ser virtuoso, será cumpridor de seus deveres, bom esposo, bom pai - como podemos ver em Emile e Sophie ou os solitários (ROUSSEAU, 1994) - e bom cidadão. Eis que natureza humana se converte em absoluto ético, e, como imperativo da virtude e da verdade, resta à educação o mérito de configurá-la às necessidades humanas que o mundo moderno proporciona. Boto (2002, p. 349) chega a dizer: "O Emílio ao nascer, é o homem do estado de natureza; o Emílio bem-educado - que aos 25 anos se despede de seu educador - é o homem civil; que vive em uma sociedade corrompida, mas que, a despeito disso, pode ser considerado apto para fundar o legítimo contrato social”. Emílio goza da liberdade de tomar parte ou de renunciar a um contrato: "Todo homem em se tornando maior e senhor de si mesmo, torna-se também senhor de renunciar ao contrato pelo qual se prende à comunidade, abandonando o país em que ela se acha estabelecida" (ROUSSEAU, 1973, p. 538).

Conforme Py (1997, p. 118), o pressuposto educacional de Emílio é: "Elevar a criança do estado de ignorância e de inaptidão nas quais se encontra ao estado de membro realizado da sociedade civil, apto, como todos os cidadãos, completar a funçáo correspondente ao estado ao qual se destina”. Outro comentador mais recente de Rousseau, Vargas (1995, p. 197), diz o seguinte: "Quando o matrimônio estiver, enfim, decidido, Emílio será obrigado a deixar Sofia para percorrer a Europa e voltar digno de ser pai e cidadão". 
Daí o valor de Emílio ou da educação (ROUSSEAU, 1973) e de Do contrato social (ROUSSEAU, 1999b) para pensar a educação como a principal condutora da perfectibilidade e, por conseguinte, educadora do amor-próprio com vistas a aproximar o homem o máximo possível de seu propósito enquanto homem social: "É assim que mesmo o homem sendo bom, os homens acabaram por tornar-se maus. Meu livro [Emílio ou da educaçâo] se dedica à busca do que seria necessário fazer para impedi-los de terminar dessa forma" (ROUSSEAU, 2005, p. 48). Malgrado a importância do tema, a possibilidade de educar o amor-próprio ainda não foi devidamente explorada pelos rousseauístas brasileiros, os quais seguem majoritariamente a tradição interpretativa francesa, deixando de lado às vezes as atuais contribuiçóes de intérpretes do mundo anglo-saxônico atuais como Frederick Neuhouser, Maximilian Forschner e Axel Honneth, cuja discussão procura explorar a problemática do amor-próprio e seu duplo significado, assim como as contribuiçóes mais antigas de Ralph Leigh, Judith Shklar e Christopher Bertram, os quais buscam em seus escritos discutir o papel de homem e cidadão na teoria social e política de Rousseau.

Como um "fenômeno social de primeira grandeza" (NEUHOUSER, 2009 apud DALBOSCO, 2011, p. 489), o amor-próprio aproxima-se um pouco do thymos platônico e constitui-se como parte intrínseca da condição humana em sociedade, reinvindicando o reconhecimento dos outros e a dignidade social (DENT, 1996) a que todos aspiram. Em vista dessa possibilidade, o papel da educação amplia-se e passa a contemplar a reversão do aspecto negativo do amor-próprio (ROUSSEAU, 1999a) para um aspecto mais nobre e, portanto, positivo (como exposto em Emílio ou da educação). Afinal, Rousseau fala de um amor-próprio "exaltado", "petulante", usando outros termos que dáo a ideia de um caráter excessivo, mas fala também de um amor-próprio "nobre", como na abertura da carta ao Sr. De Franquières: "Aqui está, senhor, esta miserável ladainha que meu humilhado amor próprio vos fez esperar tanto tempo, por não sentir que um amor próprio muito mais nobre deveria ensinar-me a sobrepujar o primeiro" (ROUSSEAU, 2005, p. 177). Tal nos permite afirmar que Rousseau jamais quis eliminar o amor-próprio, pois, como diz Dalbosco (2011, p. 492), isso "significaria o mesmo que querer pensar o homem sem suas paixôes e sem sua racionalidade e, em síntese, sem sua própria subjetividade".

É assim que Emílio, uma espécie prototípica de homem natural vivendo no meio social, tem sua formação iniciada pela educação negativa. No entanto, assim como em Aristóteles (2003), o processo deve ser orientado para a formação das virtudes humanas e, com elas, a felicidade. A diferença é que, enquanto em Aristóteles (2003) a opção é clara pelo zoón politikon, em Rousseau parece não haver opçáo, ou seja, os dois objetivos (homem natural e homem civil) coadunam para a realização da felicidade humana. 
Diante da pluralidade de ideias pedagógicas, ressalta-se a importância do pensamento de Rousseau como um rico material teórico para nos auxiliar a refletir sobre a finalidade da açáo educacional, provocando a discussáo sobre que figura humana nosso aluno apresentará e que tipo de homem nós nos propomos formar. À filosofia da educaçâo cabe a tarefa de entender as tendências e os caminhos pensados e trilhados no passado para poder sempre pensar acerca do presente em suas diversas necessidades. Por isso, nunca é demais estudar nem discutir a obra do "cidadão de Genebra", principalmente na perspectiva de tirar de seu pensamento os elementos teóricos que possam nos ajudar na árdua tarefa de reconfigurar o homem para uma sociedade melhor.

Portanto, a obra artística que pode ser prospectada no pensamento de Rousseau quanto à formação humana é, para utilizar nosso termo, a da reconfiguração. Embora uma restauração precisa que pudesse devolver à estátua de Glauco os traços minuciosos de sua figura pudesse ser a ação mais desejável, não é a mais viável. Por outro lado, a total desfiguração eliminaria completamente seus traços e resultaria na completa negação do intento de seu criador. Resta, então, uma ação nova, um empreendimento audacioso e ao mesmo tempo restaurador: dar-lhe uma nova figura. Está implícita em Emílio ou da educação (ROUSSEAU, 1973) como a forma mais autêntica de desnaturar o homem e dar-lhe uma figura apropriada à realidade que o cerca, preparando-o para melhor enfrentar os problemas concretos de sua existência, uma vez que o homem possui problemas pessoais, íntimos, assim como problemas sociais, coletivos e civis.

\section{Notas}

1. Principal personagem da obra magistral de Miguel de Cervantes (1993) El ingenioso hidalgo Don Quijote de la Mancha.

2. Príncipe Ganitzine (DEFOE, 1947, p. 444).

3. Entendendo por sistema uma totalidade dedutiva de um discurso englobando premissas e conclusões devidamente organizadas (ABBAGNANO, 2000, p. 908-909).

\section{Referências}

ABBAGNANO, N. Dicionário de filosofia. Tradução de Alfredo Bosi e Ivone Castilho Benedetti. 4. ed. São Paulo: Martins Fontes, 2000.

ARISTÓTELES. Ética a Nicômaco. São Paulo: Martin Claret, 2003. v. 53. (Coleção A Obra-Prima de Cada Autor).

BOTO, C. História, verdade e virtude em Rousseau: pacto político e ética pedagógica. Revista de História das Ideias, v. 23, 2002. 
CERVANTES, M. El ingenioso hidalgo Don Quijote de La Mancha. 39. ed. Madri: EspasaCalpe, 1993.

COBBAN, A. Rousseau and the modern state. Londres: Novello \& Co., 1964.

COTTA, S. Théorie religieuse et théorie politique chez Rousseau. In: INSTITUT INTERNATIONAL DE PHILOSOPHIE. Annales de Philosophie Politique, n. 5. Paris: PUF, 1965.

DALBOSCO, C.A. Aspiração humana por reconhecimento e educação do amor próprio em Jean-Jacques Rousseau. Educação e Pesquisa, São Paulo, v. 37, n. 3, p. 481-496, jan./ dez. 2011.

Condição humana e formação virtuosa da vontade: profundezas do reconhecimento em Honneth e Rousseau. Educação e Pesquisa, São Paulo, v. 40, n. 3, p. 799-812, jul./set. 2014.

DEFOE, D. Robinson Crusoé. São Paulo/Rio de Janeiro/Porto Alegre: W. M. Jackson, 1947. v. 1. (Coleção Grandes Romances Universais).

DELLA VOLPE, G. Rousseau e Marx: a liberdade igualitária. Tradução de António José Pinto Ribeiro. Porto: Edições 70, 1982. v. 8. (Coleção O Saber da Filosofia).

DENT, N.J.H. Dicionário Rousseau. Tradução de Álvaro Cabral. Rio de Janeiro: Jorge Zahar, 1996.

DERATHÉ, R. Les rapports de la morale et de la religion chez Jean-Jacques Rousseau. Paris: Revue Philosophique, 1949. (p. 143-173).

FRANCISCO, M.F.S. A filosofia da educação de Rousseau: uma proposta de releitura do Emílio. Cadernos de História e Filosofia da Educação, São Paulo, v. 2, n. 4, p. 35-42, 1998.

. Notas acerca da educação doméstica e educação pública no Emílio de Rousseau. Notandum 16, Porto, 2008.

JIMACK, P. La génese et la rédation de l'Émile de J.-J. Rousseau. Genebra: Institut et Musée Voltaire, 1960.

MARQUES, J.O.A. A educação musical do Emílio. Rapsódia: Almanaque de Filosofia e Arte, São Paulo, n. 2, p. 7-35, 2002.

NASCIMENTO, M.M. O contrato social: entre a escala e o programa. Discurso, São Paulo, n. 17, p. 119-129, 1988.

NEUHOUSER, F. Freedom, dependence and General Will. The philosophical review, v. 102, n. 3, jul. 1993.

PAIVA, W.A. Da reconfiguração do homem: um estudo da ação político-pedagógica na formação do homem em Jean-Jacques Rousseau. 230 f. Tese (Doutorado)-Faculdade de Educação, Universidade de São Paulo, São Paulo, 2010.

PY, G. Rousseau et les éducateurs: etude sur la fortune des idées pédagogiques de JeanJacques Rousseau en France et en Europe au XVIIIe siècle. Oxford: Voltaire Foundation, 1997. 
RANG, M. L'éducation publique et la formation des citoyens chez J.-J. Rousseau. In: ÉTUDES SUR LE “CONTRAT SOCIAL” DE J.-J. ROUSSEAU. Actes de Journées d'études tenues à Dijon, maio 1962. Paris: Sociétés les Belles Lettres, 1964.

ROUSSEAU, J.-J. Carta a Christophe de Beaumont e outros escritos sobre a religião e a moral. Organização e apresentação de José Oscar de Almeida Marques. Tradução de J. O. Q. M. et al. São Paulo: Estação Liberdade, 2005.

. Consideraçóes sobre o governo da Polônia e sua reforma projetada. Tradução de Luiz Roberto Salinas Fortes. Sáo Paulo: Brasiliense, 1982.

. Discurso sobre a origem e os fundamentos da desigualdade entre os homens. Tradução de Lourdes Santos Machado. Introduções e notas de Paul Arbousse-Bastide e Lourival Gomes Machado. São Paulo: Nova Cultural, 1999a. v. 2. (Coleção Os Pensadores).

. Do contrato social. Tradução de Lourdes Santos Machado. Introduções e notas de Paul Arbousse-Bastide e Lourival Gomes Machado. São Paulo: Nova Cultural, 1999b. v. 1. (Coleção Os Pensadores).

. Emile or on education. Introdução, tradução e notas de Allan Bloom. Nova York: Basic Books, 1979.

Paraula, 1994.

Emile e Sophie ou os solitários. Tradução de Dorothée de Bruchard. Porto Alegre: . Emílio ou da educação. 2. ed. São Paulo: Difusão Europeia do Livro, 1973.

. Oeuvres complètes. Paris: Gallimard, 1964. 4 v. (Bibliothéque de la Plêiade).

SALINAS FORTES, L.R. Paradoxo do espetáculo: política e poética em Rousseau. São Paulo: Discurso Editorial, 1997.

. Rousseau: o mundo político como vontade e representação. Revista Filosofia Politica, Porto Alegre, p. 99-116, 1985.

STAROBINSKI, J. Jean-Jacques Rousseau: a transparência e o obstáculo. Tradução de Maria Lúcia Machado. São Paulo: Companhia das Letras, 1991.

Editorial, 1997.

Paradoxo do espetáculo: política e poética em Rousseau. São Paulo: Discurso . The invention of liberty. Nova York: Rizzoli International Publications, 1987.

VARGAS, Y. Introduction à l'"Emile" de Rousseau. Paris: Presses Universitaires de France, 1995.

Recebido em 20 de junho de 2014.

Aprovado em 18 de fevereiro de 2016. 